\title{
The effectiveness of the new education and training policy in addressing the learning crisis in Tanzania
}

\author{
Kitila Mkumbo \\ School of Education, \\ University of Dar es Salaam, \\ P.O. Box 35048, Dar es Salaam, Tanzania \\ Email: kitilam@udsm.ac.tz \\ Email:kitilam@yahoo.com
}

\begin{abstract}
Using content analysis research method, the paper analyses the content of the new education and training policy in Tanzania, with a view to examining the extent to which it is geared towards promoting learning outcomes. The analysis shows that the new policy embodies some significant changes that will guide the Tanzanian education agenda for a foreseeable future. Notably, the newly introduced structure of education seems appropriate and in line with international trends regarding the number of years that children are expected to spend in basic education. Nevertheless, the main focus of the policy statements seems to be on improving access rather than learning outcomes. In particular, the policy is largely silent on the most important driver of learning: the quality of teachers. As such, it is concluded that the new policy does not seem to be adequately geared towards addressing the apparent learning crisis in Tanzania.
\end{abstract}

Keywords: Tanzania; education and training policy; policy statements; learning outcomes.

Reference to this paper should be made as follows: Mkumbo, K. (2017) 'The effectiveness of the new education and training policy in addressing the learning crisis in Tanzania', Int. J. Management in Education, Vol. 11, No. 3, pp.347-366.

Biographical notes: Kitila Mkumbo is an Associate Professor in Psychology and Learning at the School of Education at the University of Dar es Salaam, having served in this university for the past 13 years. He also previously served as senior consultant in education for Twaweza East Africa.

\section{Introduction}

Education is widely viewed as an important facilitative vehicle for individual development and social transformation. It has become part of the humanity and society to the extent that it would be eccentric to think of the existence of the society without the provision of formal education. 
The 1948 Universal Declaration of Human Rights recognises education as a human right. This right was established as an international law in the 1996 International Covenant on Economic, Social and Cultural Rights (Article 13). Since then a series of other international declarations, such as the Jomtien World Declaration and the Framework for Action on Education (1990) and the Dakar Framework for Action (2000) on education for all, have been made that reaffirm the right to education.

Owing to its importance to human and societal development, most international laws on education emphasise and promote the provision of basic education for free. For example, the 1996 International Covenant on Economic, Social and Cultural Rights (Article $13[2 \mathrm{~b}]$ ) states that 'primary education shall be compulsory and available for free'. This is also widely echoed by other international declarations on education.

According to the UNESCO and UN Committee on Economic, Social, and Cultural Rights (1999), education is an important vehicle through which economically and socially marginalised adults and children can overcome poverty and gain the means to fully participate in the social and economic development processes for their communities. Education is also viewed as a prerequisite for individuals to exercise other civil, political, economic and social rights.

Indeed, education is arguably the most significant determinant of economic development in the modern world for both individuals and countries, and it is the main distinguishing characteristics in the level of development between developed and developing countries (Aturupane et al., 2014). Aturupane et al. (2014, p.9) observe that 'well-educated individuals, especially women, are better able to control their fertility and family health, resulting in reduced child, infant and maternal mortality, and higher life expectancy'. Furthermore, education has been associated with social mobility by creating opportunities through enhanced skills, social status and access to networks (Organisation for Economic Cooperation and Development [OECD], 2013). Learning also leads to reduction of crime rates, increase in civic participation and social cohesion (Green and Preston, 2001).

Nevertheless, benefits of education are not due to mere schooling but they depend on the quantity and quality of learning. Hanushek and Woessmann (2012) analysed trends in schooling and economic growth in Latin American countries. They found that increase in productivity was related to a more educated workforce but more education, as measured in years of schooling, was insufficient; it was more learning that led to more growth. For example, they found that 100 points of PISA (an international assessment that measures 15 -year-old students' reading, mathematics, and science literacy every three years) scores translates into $1.74 \%$ higher annual per capita GDP.

How education is organised and what role it plays in a country is largely a function of the education policy. In this paper, I analyse the new education and training policy (2014) in Tanzania with a view to illuminating the present and future directions of education in the country. More specifically, I analyse the extent to which the new policy is geared towards promoting learning outcomes.

An education policy is an important tool for guiding the engagement of stakeholders in the delivery of education. It is the instrument through which the status quo expresses the scope, form and nature of the education system in a country (Grimley, 1986). Through the education policy document, a country details the statement of values that it intends to impart from one generation to another over a given period of time. 
Ideally, as argued by Grimley (1986), the presence of an education policy denotes an admission of an imperfect state. Consequently, the education policy is expected to provide the basis for change and the range of possibilities for doing so. Therefore, a national education policy establishes the main goals and priorities in education to be pursued by the Government of the day, as well as delineating responsibilities for various levels of implementation both at national and local government levels. Furthermore, the education policy embodies the strategy that specifies how the policy goals are to be attained.

\section{The state of education in Tanzania: the looming crisis in learning}

The education system in Tanzania can be described as 2-7-4-2-3+, which translates as two years of pre-primary education, seven years of primary education, four years of ordinary secondary education, two years of advanced secondary education and three or more years of tertiary and higher education. Until 2015, basic education consisted of seven years of primary education covering children aged 7-13 years. Nevertheless, the new policy in education and training of 2014 makes secondary education a part of compulsory and fee-free basic education beginning 2016.

Figure 1 Pass rates in PSLE and CSEE between 2005 and 2014

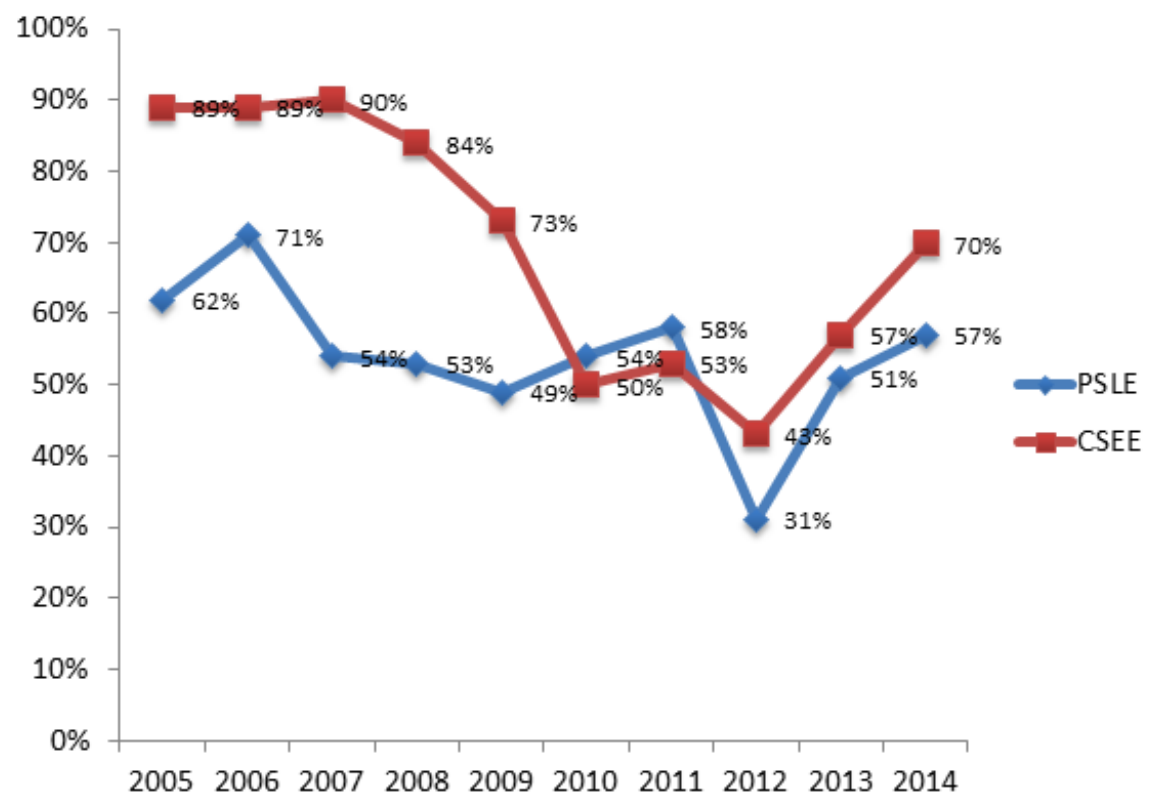

Source: Author's calculations from Pre-Primary, Primary and Secondary Education Statistics Data (URT, 2014)

In recent years, Tanzania has made tremendous achievements in increasing the enrolment at all levels. For example, the number of primary schools has increased from 14,256 in 2005 to 16,345 in 2014 . The increase in the number of schools has resulted in a rapid 
increase in the enrolment rate. The enrolment trend shows that the number of primary school students increased from 7.54 million in 2005 to 8.23 million students in 2014. The number of secondary school students more than doubled in a period of ten years from 524,325 in 2005 to $1,804,056$. By 2014, the Gross Net Enrolment (GER) for primary schools was $93.3 \%$ and the GER for secondary education was $41.7 \%$. The corresponding Net Enrolment Ratio (NER) for primary education and secondary education in 2014 was $84.4 \%$ and $32.9 \%$, respectively (URT, 2014).

The expansion of access to basic education has not been in line with the improvement in learning. Figure 1 summarises the trends in pass rates between 2005 and 2012 in the Primary School Leaving Examinations (PSLE) and the Certificate of Secondary Education Examinations (CSEE). It is clear from this table that pass rates have been plummeting over the years and especially beginning the year 2009 at both PSLE and CSEE. For example, pass rates in CSEE dropped from $89.3 \%$ in 2005 to only $43.1 \%$, while PSLE pass rates dropped from $70.5 \%$ in 2006 to only $30.7 \%$ in 2012 . There were notable changes in 2013 and 2014 results mainly due to the change in the grading system in which pass rates were lowered, especially for secondary school examinations.

Another notable indicator of the state of learning in schools in Tanzania in recent years is the Uwezo ${ }^{1}$ assessments, which examine children's (aged 7-16) competencies in reading and numeracy. Table 1 summarises the results of Uwezo assessment tests for four years (Uwezo, 2010-2013). As this table shows, the performance in all three subjects (Kiswahili, English and Mathematics) is generally poor. With the exception of 2013, less than a third of children in Standard 3 could read a Standard 2 story in Kiswahili. The performance was particularly poor for English in which less than a quarter of Standard 3 children could read a Standard 2 story in English. The performance in Mathematics has been fluctuating but it has equally been poor whereby less than a quarter of Standard 3 children could perform a basic numeracy test meant for Standard 2 in 2010; the figure was $36.9 \%$ in 2011 and $31.9 \%$ in 2013 . The results were slightly better in 2012 whereby $44.4 \%$ of children in Standard 3 children could perform a basic numeracy task pegged at Standard 2 level.

Table 1 Performance in Uwezo assessment tests by grades 2010-2013

\begin{tabular}{lccccccccccccc}
\hline \multirow{2}{*}{ Subject } & \multicolumn{3}{c}{2010} & \multicolumn{4}{c}{2011} & \multicolumn{3}{c}{2012} & \multicolumn{3}{c}{2013} \\
\cline { 2 - 13 } & III & VII & All & III & VII & All & III & VII & All & III & VII & All \\
\hline Kiswahili & 32.7 & 81 & 42.2 & 28.3 & 76.2 & 42.2 & 26.2 & 76 & 41.1 & 45.4 & 80.4 & 55.8 \\
English & 7.7 & 50.9 & 18.7 & 11.5 & 48.4 & 27.5 & 11.9 & 53.2 & 24.2 & 19.1 & 47.8 & 30.3 \\
Math & 18.5 & 68.5 & 30.8 & 36.9 & 85.0 & 49.5 & 44.4 & 89.1 & 55.6 & 31.9 & 70.8 & 44.4 \\
\hline
\end{tabular}

In July 2013, the first National Baseline Assessment for 3Rs (Reading, Writing, and Arithmetic) Using Early Grade Reading Assessment (EGRA and Early Grade Mathematics Assessment (EGMA) were conducted with the purpose of monitoring the achievement levels in foundational skills (USAID, 2014). These assessment tests offer an opportunity to determine whether children are developing the foundational skills upon which all other literacy and mathematical skills build, and provide a basis for improving the quality of education. 
The EGRA and EGMA assessment tests were administered to 2266 Standard 2 randomly selected from 200 schools, which were also randomly selected representing national, rural-urban and gender diversity. The results showed that about $60 \%$ of students were able to read 18 words in Kiswahili correctly. Furthermore, $40 \%$ of students were unable to answer a single question correctly. The minimum international benchmark for this level is that students should be able to answer at least $80 \%$ of the questions correctly.

In English, the performance was particularly poor, with $94 \%$ of the students unable to answer a single question correctly. This means that only six $(6 \%)$ of the students have a basic level of comprehension in English at Standard 2 level.

In Mathematics, $60 \%$ of the children were able to perform basic procedural tasks in Mathematics (addition and subtraction). Nevertheless, students had difficult performing conceptual tasks in Mathematics, where $58 \%$ of the tested children were unable to undertake basic conceptual task in Mathematics. This may imply that teaching and learning are more inclined towards memorisation than understanding.

Another important source of learning performance in Tanzania and Africa in general is the Southern and Eastern Africa Consortium for Monitoring Educational Quality (SACMEQ). This the consortium of 15 ministries responsible for education in Southern and Eastern African countries, policy-makers and researchers together with the UNESCO's International Institute for Educational Planning (IIEP), which aim to improve the research capacity and technical skills of educational planners. Data generated from school surveys are expected to give capacity to ministries and policy makers in education to monitor general conditions of schooling and quality of basic education.

Since 1995, SACMEQ has been conducted research on education capturing a number of indicators related to the quality of education, including reading and numeracy performance among Grade 6 learners. SACMEQ started with seven countries and it has now expanded to include 15 countries in Southern and Eastern Africa. Thus far three reading and numeracy performance assessments have been conducted with data reported in 2000, 2004 and 2007. The results are scored relative to a mean score of 500 and a standard deviation of 100, implying that for a country to indicate improve it must have moved beyond the mean score and it will be considered to have achieved significantly with an increase of 100 points over a period of four years.

Table 2 summarises the reading and numeracy scores for two SACMEQ assessments in 2004 and 2007. For both rounds, Tanzania performed relatively higher than the mean, and improved its performance considerably higher than other countries in East Africa (Kenya and Uganda) in both reading and mathematics scores.

The trend in learning achievement as highlighted above is quite revealing. The majority of children attending the education system are not achieving the expected competencies at the right level. Indeed, the results of Uwezo assessments over the past five years show that, by the end of the primary school learning cycles, almost a quarter of the children have not mastered a Standard 2 level curriculum in reading and numeracy. This puts them at the risk of missing out further education opportunities and critical life preparatory skills for successful life in future. 
Table 2 Reading and Math achievement scores for SACMEQ II and III

\begin{tabular}{|c|c|c|c|c|c|}
\hline \multirow{3}{*}{\multicolumn{2}{|c|}{ Country }} & \multicolumn{4}{|c|}{ Pupil scores } \\
\hline & & \multicolumn{2}{|c|}{2000} & \multicolumn{2}{|c|}{2007} \\
\hline & & \multirow{2}{*}{$\begin{array}{c}\text { Reading } \\
521.1\end{array}$} & \multirow{2}{*}{$\begin{array}{c}\text { Mathematics } \\
512.9\end{array}$} & \multirow{2}{*}{$\begin{array}{c}\text { Reading } \\
534.6\end{array}$} & \multirow{2}{*}{$\begin{array}{c}\text { Mathematics } \\
520.5\end{array}$} \\
\hline 1 & Botswana & & & & \\
\hline 2 & Kenya & 546.5 & 563.3 & 543.1 & 557.0 \\
\hline 3 & Lesotho & 451.2 & 447.7 & 467.9 & 476.9 \\
\hline 4 & Malawi & 428.9 & 432.9 & 434.0 & 447.0 \\
\hline 5 & Mauritius & 536.4 & 584.6 & 573.5 & 623.3 \\
\hline 6 & Mozambique & 516.7 & 530.0 & 476.0 & 483.8 \\
\hline 7 & Namibia & 448.8 & 430.9 & 497.0 & 471.0 \\
\hline 8 & Seychelles & 582.0 & 554.3 & 575.0 & 551.0 \\
\hline 9 & South Africa & 492.3 & 486.1 & 495.0 & 495.0 \\
\hline 10 & Swaziland & 549.0 & 541.0 & 529.6 & 516.5 \\
\hline 11 & Tanzania (Mainland) & 545.9 & 522.0 & 578.0 & 553.0 \\
\hline 12 & Zanzibar & 478.2 & 478.1 & 536.8 & 489.9 \\
\hline 13 & Uganda & 482.4 & 506.3 & 479.0 & 482.0 \\
\hline 14 & Zambia & 440.1 & 435.2 & 434.4 & 435.2 \\
\hline 15 & Zimbabwe & - & - & 507.7 & 519.8 \\
\hline
\end{tabular}

Source: Author's calculation from SACMEQ reading and Mathematics achievement scores available at http://www.sacmeq.org/ReadingMathScores

\section{Objectives}

The purpose of this paper was to analyse the contents of the new (2014) education and training policy in Tanzania with a view to establishing the extent to which it is set to address the learning crisis in Tanzania. The paper addresses three key research questions. Firstly, how do learning outcomes feature as a measure of the performance of the Tanzanian education system? Secondly, what are the envisaged measures in the policy for improving learning outcomes? Thirdly, to what extent are these measures informed by evidence on what works in promoting learning outcomes?

The analysis is important both theoretically and for practical purposes. Practically, given the apparent learning crisis in Tanzania and other African countries, the analysis will provide policy-makers and implementers a basis for assessing the relevance of the envisaged strategies in addressing the learning crisis. This is particularly important given that there is a new Government in the country and which has placed education at the top of its development agenda. Theoretically, the analysis is important in providing researchers with a tool for critical evaluation of the relevance of the policy in addressing education challenges in the country. Additionally, the analysis provides an important framework for educational policy analysis. 


\section{Methodology}

Qualitative content analysis was employed to analyse the content of the education and training policy in Tanzania. Qualitative content analysis is a research method for the subjective interpretation of the content of text data through the systematic classification process of coding and identifying themes or patterns (Hsieh and Shannon, 2005). Text data might be in verbal, print or electronic form. The target content of this analysis was the Tanzania education and training policy of 2014.

According to Hsieh and Shannon, there are three major approaches to content analysis, namely conventional content analysis, directed content analysis and summative content analysis. In conventional content analysis, codes are defined during data analysis and they are derived from the field data (as is the case when analysing transcriptions from interviews and focus groups). In directed content analysis, codes are derived from theory or directly from research findings.

For the analysis reported in this paper, I adopted the summative content analysis approach. This approach focuses on key words (rather than codes), which are derived from interest of researchers or review of literature. The key words are identified before and during data analysis. Accordingly, in this analysis, the researcher was interested in key words related to learning outcomes that are embodied in the education and training policy. The interest was on key words that are associated with improving learning outcomes. We were, therefore, looking for categories in the policy documents (usually written as policy statements) that relate to learning outcomes.

Our interest in the analysis was not only in the counting of the categories, but also in the interpretation of the contextual meaning of the categories. As such, the content analysis was approached inductively rather than deductively (Elo and Kyngas, 2008) and included what Hsieh and Shannon (2005) termed latent content analysis, which they define it as the process of interpretation of content. Accordingly, the focus of this analysis was on uncovering the extent to which the policy statements were appropriately focused on improving learning outcomes in basic education in Tanzania.

Three main steps were adopted in the content analysis of the policy document. Firstly, in line with Mayring's (2014) content analysis framework, the reference material for analysis was identified, in this case, the 2014 education and training policy in Tanzania. Secondly, the description of what Mayring calls 'formal characteristics of the material' was provided. This is provided in form of a synopsis of the contents of the education and training policy. Thirdly, the analytical elements were identified and examined using both quantitative and qualitative content analysis approaches. Quantitatively, I identified and quantified the analytical units, and qualitatively, I provided the contextual interpretation of the identified analytical units.

One limitation of the content analysis methodology as used in this analysis is that the categorisation of the policy statements was based on the researcher's judgement without being verified by other experts. Nevertheless, as argued by Elo and Kyngas (2008), when dealing with non-voluminous text data, as was the case in this research, further verification by other experts may not be an issue. Additionally, in this analysis, only one source of text data was used, namely the education and training policy. As such, consistency in coding and categorisation could not emerge as an issue. 


\section{Findings}

\subsection{Key features of the 2014 education and training policy}

Ideally, a policy is made as response to addressing an identified problem. Thus, policies are preceded with an analysis of the background on the context of the problem and identification of the root causes of the problem. This kind of analysis should, ideally, be theoretical and/or evidence based.

In Tanzania, the policy development process is supposed to use a bottom-up approach and to be participatory and widely consultative (Mattee, 2007). Nevertheless, in practice, the education policy-making process is usually centralised with minimal engagement of stakeholders other than Government bureaucrats (Buchert, 1997). Buchert observes that, though the policy-making process is usually a centralised business, the implementation process heavily relies on active participation of multiple stakeholders. Nevertheless, the politics of education policy development in Tanzania is not the subject of the present analysis. This subject has been well examined by Buchert (1997). The present analysis focuses on the content of the policy rather than its development process.

Five features characterise a typical government policy in Tanzania. These are background information; situational analysis/existing challenges; rationale; objectives, vision and mission; issues and policy statements; and implementation framework and action plan. Consistent with this framework, the 2014 new education and training policy, which is the subject of the present analysis, is presented in five main chapters, namely Introduction in Chapter 1; the importance and purpose of the policy in Chapter 2; policy statements in Chapter 3; legal framework in Chapter 4; and institutional framework in Chapter 5. The components of these chapters are highlighted below.

Chapter 1 on introduction highlights five major areas. Firstly, the chapter presents the scope of the new policy in which it indicates that the policy covers all levels of education, from pre-primary level to higher education. The scope of the new policy is broader than the previous 1995 policy. Previously, there were three major policies related to education and training covering basic education, technical education and higher education. The new policy consolidates all policies related to education and training into one policy.

The second area in the chapter reviews the achievements underscored in the 19 years of implementation of the 1995 education and training policy. Most of the achievements underscored focus on the expansion of educational opportunities at all levels, from primary to higher education. Understandably, the review of achievements is largely silent on the gains achieved regarding quality of education. This is because, while the enrolment rates have been increasing at all levels during the implementation period of the policy, learning outcomes have been deteriorating as has been highlighted in the previous sections of this paper.

The third area in this chapter highlights the major education reforms that took place during the lifespan of the 1995 policy. Notably, these include the introduction of the Primary Education Development Programme (PEDP) and Secondary Education Development Programme (SEDP), which oversaw massive expansion of primary and secondary education opportunities.

The fourth area in the chapter highlights key challenges experienced during the implementation of the 1995 policy. These include the deterioration of school infrastructure and inputs, shortage of teachers, poor integration of information and communication 
technology in teaching and learning, limited opportunities for higher education, outdated curriculum that does not match with ongoing economic and social development reforms and poor coordination among the various authorities handling the education sector. Interestingly, throughout the situational analysis, there is no explicit mention or acknowledgement of the learning crisis as a critical challenge facing the education system in Tanzania.

The chapter concludes by providing a justification for the new policy. Two important justifications for the new policy are provided. Firstly, the chapter highlights the need to bring the education and training policy in line with other national development frameworks. During the 19 years of the implementation of the new policy, several development policy frameworks took place, notably the National Strategy for Growth and Poverty Reduction (NSGPR), which is also popularly known in Kiswahili as MKUKUTA (Mkakati wa Kukuza Uchumi na Kupunguza Umaskini Tanzania). Secondly, the chapter observes the need to review the structure and system of education so as to bring it at par with international trends. In particular, it is observed that children in Tanzania start formal education too late, and exit it too early and that the education system did not prepare them adequately for the world of work. Notably, the problem of poor learning outcomes is not appropriately acknowledged and does not form a basis for the justification of the new policy.

Chapter 2 provides the vision and mission statements, as well as the principle objectives of the new policy. The vision of the new policy is to 'have educated Tanzanians with the right knowledge, skills, competencies and attitudes so that they contribute productively in the national development processes'. The mission is to improve the quality of education by putting in place policy frameworks and procedures that will facilitate wide access to educational opportunities and to promote a society with lifelong learning attitudes and habits as important avenues for them to contribute in the national development agenda. The specific objectives of the policy are to have:

i A flexible structure and system of education that provides Tanzanians with various avenues for learning and relearning to acquire basic academic and professional competencies;

ii Quality education and training systems that meet the regional and international standards;

iii Expanded access to educational opportunities at all levels of education;

iv Adequate levels of human resource in line with national development needs;

V Effective management and supervision of education and training;

vi Sustainable financing system of education and training; and

vii A flexible education and training system that recognises and addresses cross-cutting issues.

Chapter 3 embodies various policy statements organised according to the above stated specific objectives (these are further examined below). Chapters 4 and 5 cover the legal and institutional frameworks, respectively. They highlight some of the laws and related policies that will need to be amended or enacted for the policy to be effectively implementable. 


\section{The effectiveness of the policy in addressing the learning crisis in Tanzania}

Evidently, the new education and training policy is positively ambitious in transforming the education system in Tanzania. It radically expands the threshold of basic education from seven years to ten years. This means that secondary education, in addition to primary education, becomes compulsory and fee-free. This is a welcome development because it is set to increase the enrolment in second education multiple times and bring Tanzania at par with other countries in the East and Southern African Region.

Additionally, the new policy makes pre-primary education a part of the formal basic education, which will last for between one and three years, between the age of 3 and 5 . This is also an important development because early childhood education forms a basis for and has positive consequences on later learning (Nores and Bernett, 2010).

The other notable development in the new policy is the medium of teaching and learning. Since independence, Tanzania has used two languages in education: Kiswahili and English. Kiswahili has been used as a medium of teaching and learning in primary education, while English has been used as the medium of teaching and learning in postprimary education. The new policy recognises the use of both languages in teaching and learning at all levels of education. Indeed, for the first time since independence in 1961, the new policy attempts to promote the use of Kiswahili as a medium of instruction at all levels of education and training as it declares:

The national language of Kiswahili shall be used in teaching and learning at all levels of education and training and the government shall make provisions to facilitate the use of this language to be sustainable and effective in the provision of education and training that is beneficially effective nationally and internationally. (Policy Statement 3.2.19, p.38)

In examining the relevance of the new policy in promoting learning outcomes, I analysed the content of the issues and policy statements as key categories in the content analysis. Consistent with the summative content analysis approach (Hsieh and Shannon, 2005), I analysed the relevance of the policy issues and statements in driving learning outcomes at two levels.

First, consistent with the two intended outcomes of the education process, schooling (access) and learning, I analysed the focus of each of the policy statement alongside this categorisation. Second, I analysed the focus of each policy statement with respect to the level of contribution to and extent of fitness in what is known in the literature to be evidence-based drivers of learning outcomes.

The literature shows a multitude of factors that are associated with learning outcomes (quality of education). These can be grouped into seven main categories, namely home environment, parental involvement in their children education, pre-school attendance, school resourcefulness (teaching and learning environment), school leadership, relevance of curriculum content and quality of teachers (Vegas and Petrow, 2008; Masino and Nino-Zarazua, 2015; Hungi, 2011). An education policy is particularly effective in improving the factors related to schools (all of the above factors except home environment and parental involvement).

In this analysis, we examined the focus of the policy statements in line with the above school related drivers of learning outcomes and the likely impact of each policy statement with respect to the extent to which it is expected to lead improvement in: access and inclusiveness and/or learning outcomes. 
Overall, there are 50 policy statements in response to 28 issues related to education and training (see Appendix). In Mayring's language we call these 'analytical units'. Of the 50 policy statements, $29(63 \%)$ seem to be focused on inputs and rated as having a likelihood of improving access and inclusiveness in education (see Figure 2). 17 (37\%) statements seem to lean towards learning outcomes. The other four statements are focused on other aspects such as improving governance and societal impact in general.

Figure 2 Proportion of policy statements focusing on improving access and learning outcomes (see online version for colours)

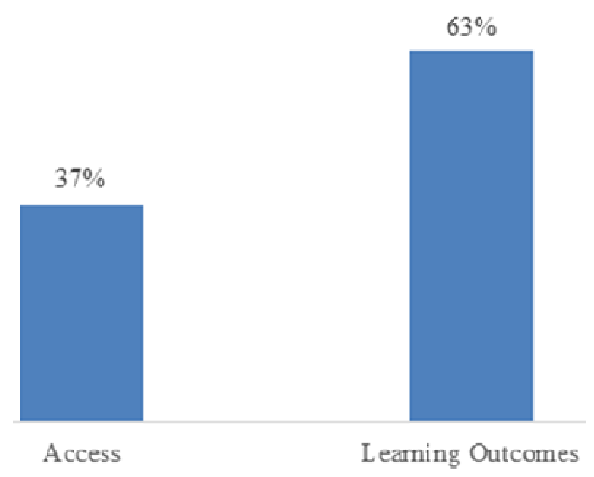

When the policy statements were analysed with respect to the five school-related factors associated with learning outcomes it emerged that, as Figure 3 shows, the majority (12, $41 \%$ ) of the policy statements were focused on school resourcefulness (teaching and learning environment) and curriculum content $(11,38 \%)$, followed by school leadership $(3,10 \%)$, quality of teachers $(2,7 \%)$ and pre-school attendance $(1,3 \%)$. The other 21 statements were related to other factors such as home environment and parental involvement, which, arguably, an education policy cannot have significant impact in influencing them.

Figure 3 Proportion of factors associated with learning outcomes addressed in the Tanzania education and training policy (see online version for colours)

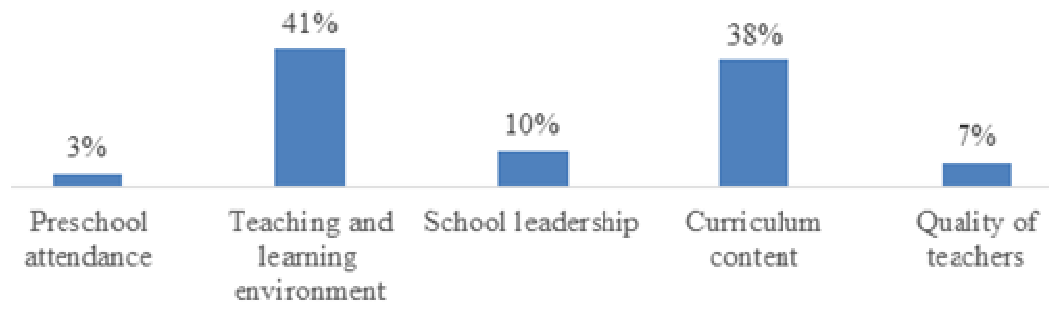

Curiously, while research shows that 'teacher quality is the single most important school variable influencing student achievement' (Leu, 2004; Desimone et al., 2002; Rivkin et al., 2005), the analysis shows that only two policy statements focus on improving quality of teachers. These are 'The Government shall improve the quality of teacher recruitment in order to fulfil the needs of teachers and other human resource in the education and training sector' (statement No. 35) and 'The Government shall ensure that the teaching profession ethical attributes are adhered to at all levels of education and training' (statement No. 40). 
Indeed, none of the statements on teachers makes reference to the four teacher quality attributes, namely teacher qualifications, teacher characteristics, teacher practices and teacher effectiveness (Goe and Stickler, 2008).

In the light of the analysis in this paper, it can be argued that the new education and training policy is not sufficiently focused on learning. Consequently, its effectiveness in improving the quality of education in Tanzania would be clearly limited. This is to say that, even if it were to be implemented efficaciously, the new policy is not likely to address the apparent learning crisis in Tanzania in the near future.

The lack of focus on learning outcomes in the new education and training policy is largely inherent in the conceptualisation of the policy. In the background section, the policy failed to appropriately locate the current context of education in Tanzania. For example, the main challenge highlighted in the background section of the policy is the poor access to education, especially at the secondary education level. While this is partly true, the main challenge facing the education system in Tanzania over the past decade has been the deteriorating learning outcomes. It is therefore not surprising that most of the policy statements focus on inputs, with a consequential likelihood of improving access and inclusiveness in education rather than learning outcomes.

Conclusively, the new policy embodies some significant changes that will guide the Tanzanian education agenda for a foreseeable future. Notably, the newly introduced structure and system of education seems appropriate and in line with international trends regarding the number of years that children are expected to spend in basic education. Nevertheless, there are clear gaps with respect to the focus areas of the policy, which seem to focus on improving access to educational opportunities rather than on learning outcomes. As such, the policy does not seem to be adequately aligned to addressing the deepening crisis in learning in Tanzania.

While the findings of this study may be applicable in other African settings, generalisation cannot be guaranteed and should be done cautiously because they are derived from a case study. The analysis is based only on one policy document, which cannot be said to be similar in any form to other educational policy documents in other countries. Nevertheless, the methodological approach can be employed to analysis of other (educational) policy documents in other similar settings.

\section{References}

Aturupane, H., Savchenko, Y., Shojo, M. and Larsen, K. (2014) South Asia Human Development Sector. Sri Lanka: Investment in Human Capital, Discussion Paper Series No. 69, World Bank Group, Washington, DC. Available online at: http://www-wds.worldbank.org/external/ default/WDSContentServer/WDSP/IB/2014/08/08/000470435_20140808130053/Rendered/P DF/899230NWP0P1130ent0in0Human0Capital.pdf

Buchert, L. (1997) Education Policy Formulation in Tanzania: Co-ordination between the Government and International Aid Agencies, UNESCO - International Institute for Educational Planning, Paris. Available online at: http://unesdoc.unesco.org/images/0010/ 001097/109738eo.pdf

Desimone, L.M., Porter, A.C., Caret, M.S., Yoon, K.S. and Birman, B.F. (2002) 'Effects of professional development on teachers' instruction: results from a three-year longitudinal study', Educational Evaluation and Policy Analysis, Vol. 24, No. 2, pp.81-112. Available online at: http://outlier.uchicago.edu/computerscience/OS4CS/landscapestudy/resources/ Desimone-Porter-Garet-Yoon-and-Birman-2002.pdf 
Elo, S. and Kyngas, H. (2008) 'The qualitative content analysis process', Journal of Advanced Nursing, Vol. 62, No. 1, pp.107-115, doi:10.1111/j.1365-2648.2007.04569.x.

Goe, L. and Stickler, L.M. (2008) Teacher Quality and Student Achievement: Making the Most of Recent Research, Research and Policy Brief, National Comprehensive Center for Teacher Quality, Washington, DC.

Green, A. and Preston, J. (2001) 'Education and social cohesion: re-centering the debate', Peabody Journal of Education, Vol. 76, No. 4, pp.247-284.

Grimley, J. (1986) 'Critical educational policy analysis: a discussion of perspectives', Australian Journal of Teacher Education, Vol. 11, No. 2, pp.18-26.

Hanushek, E.A. and Woessmann, L. (2012) 'Do better schools lead to more growth? Cognitive skills, economic outcomes, and causation', Journal of Economic Growth, Vol. 17, pp.267-321, doi:10.1007/s10887-012-9081-x.

Hsieh, H.F. and Shannon, S.E. (2005) 'Three approaches to qualitative content analysis', Qualitative Health Research, Vol. 15, No. 9, pp.1277-1288, doi:10.1177/1049732305276687.

Hungi, N. (2011) Accounting for Variations in the Quality of Primary School Education, SACMEQ Working Paper No. 7. Available online at: http://www.sacmeq.org/sites/ default/files/sacmeq/publications/07_multivariate_final.pdf

Leu, E. (2004) Developing a Positive Environment for Teacher Quality, Working Paper No. 3, EQUIP-Study on School-based Teacher Inservice Programs and Clustering of Schools. Available online at: http://www.equip123.net/docs/working-p3.pdf

Masino, S. and Nino-Zarazua, M. (2015) What Works to Improve the Quality of Student Learning in Developing Countries? WIDE Working Paper, World Institute for Development Economics Research, Helsinki, Finland. Available online at: https://www.wider.unu.edu/sites/default/ files/wp2015-033.pdf

Mattee, A. (2007) Study on Options for Pastoralists to Secure Their Livelihoods Current Policy Making Processes in Tanzania, Report submitted to CORDS (October 2007). Available online at: http://www.tnrf.org/files/E-INFO-RLTF_VOL2-PART1_Mattee-A_2008_Current_Policy_ Making_in_Tanzania.pdf

Mayring, P. (2014) Qualitative Content Analysis: Theoretical Foundation, Basic Procedures and Software Solution. Available online at: Available online at: http://nbnresolving.de/urn:nbn:de:0168-ssoar-395173

Nores, M. and Barnett, W.S. (2010) 'Benefits of early childhood interventions across the world: (under) investing in the very young', Economics of Education Review, Vol.29, No.2, pp.271-282.

OECED (2013) Education today 2013: The OECD perspective, OECD Publishing. Available online at: http://abdigm.meb.gov.tr/meb_iys_dosyalar/2013_12/20023619_educationtoday201 3theoecdperspective.pdf

Rivkin, S.G., Hanushek, E.A. and Kain, J.F. (2005) 'Teachers, schools and academic achievement', Econometrica, Vol. 73, No. 2, pp.417-458. Available online at: http://econ.ucsb.edu/ jon/ Econ230C/HanushekRivkin.pdf

URT (United Republic of Tanzania) (2014) Sera ya elimu na mafunzo [Education and training policy], Ministry of Education and Training, Dar es Salaam.

USAID (United States Agency for International Development) (2014) National Baseline Assessment for the 3Rs (Reading, Writing, and Arithmetic) Using EGRA, EGMA, and SSME in Tanzania, Study Report, USAID, Tanzania.

Uwezo (2010-2013) Are Our Children Learning? Annual Learning Assessment Reports 20102013, Uwezo Tanzania, Dar es Salaam.

Vegas, E. and Petrow, J. (2008) Raising Student Learning in Latin America: The Challenge for the 21st Century, The World Bank, Washington, DC.

\section{Note}

1 Uwezo assessments are citizens and household-based assessments of literacy and numeracy for children aged 6-16 years conducted in Uganda, Tanzania and Kenya. 
Appendix: Categorisation of policy statements into school factors related to learning outcomes

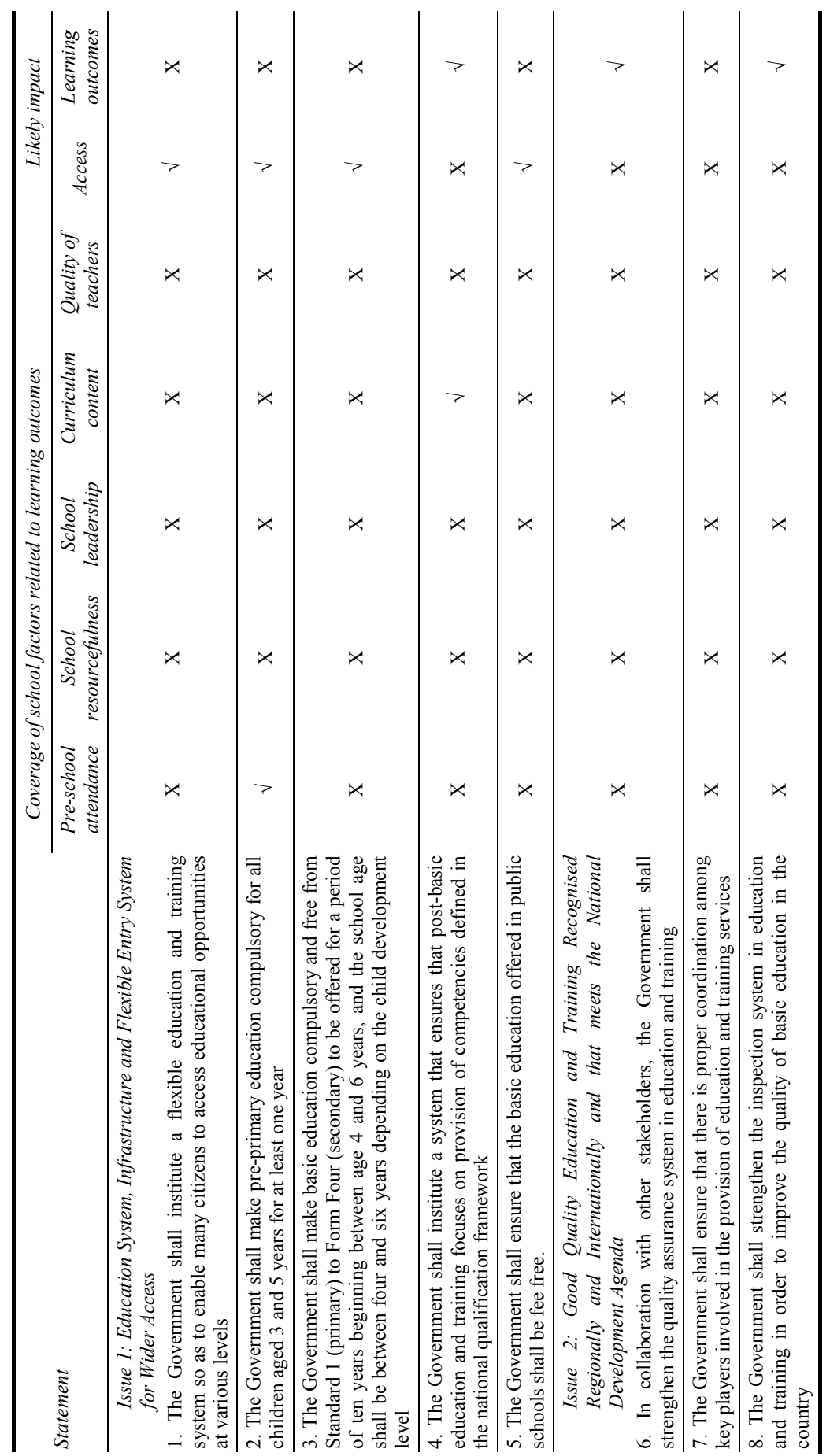


Appendix: Categorisation of policy statements into school factors related to learning outcomes (continued)

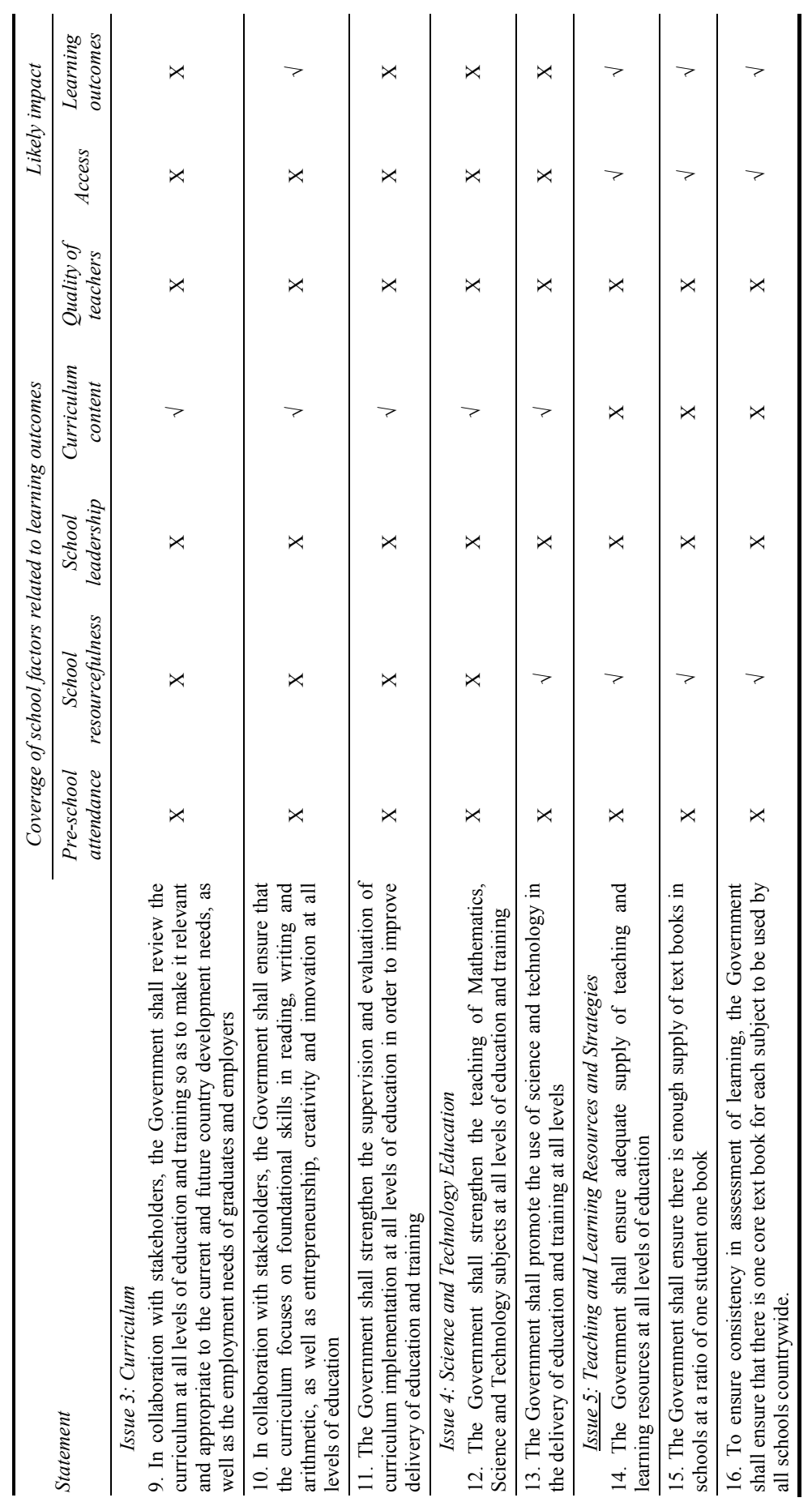


Appendix: Categorisation of policy statements into school factors related to learning outcomes (continued)

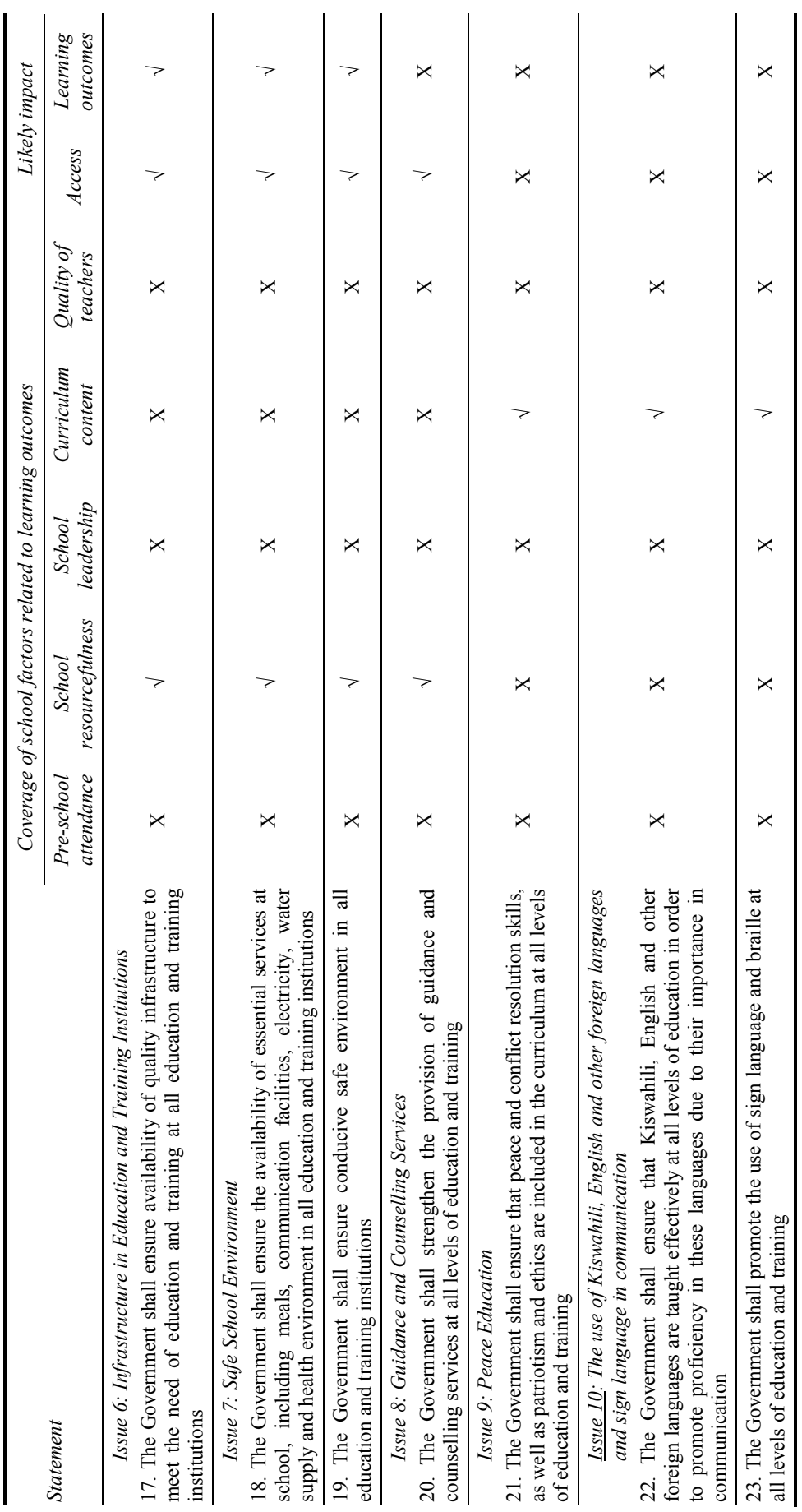


Appendix: Categorisation of policy statements into school factors related to learning outcomes (continued)

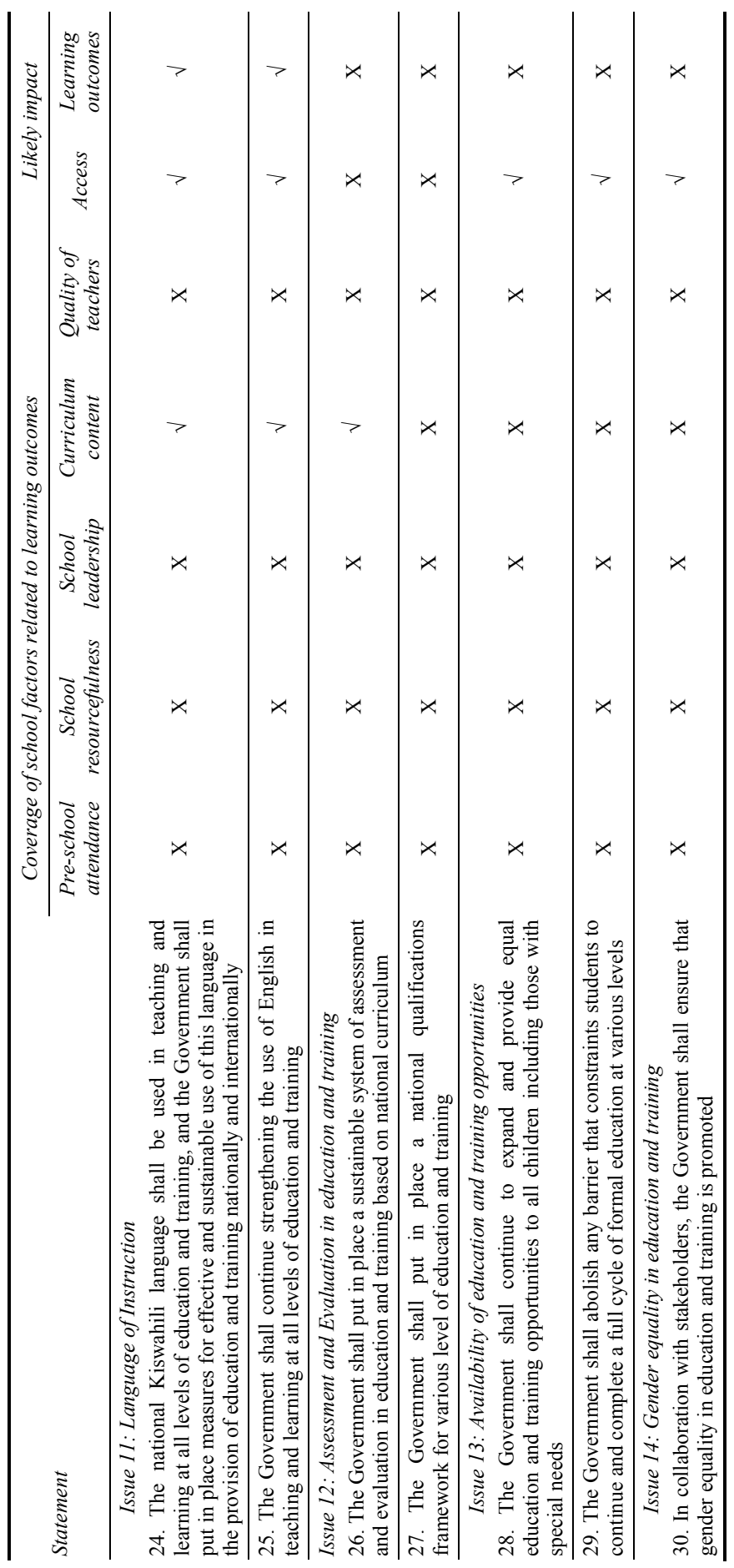


Appendix: Categorisation of policy statements into school factors related to learning outcomes (continued)

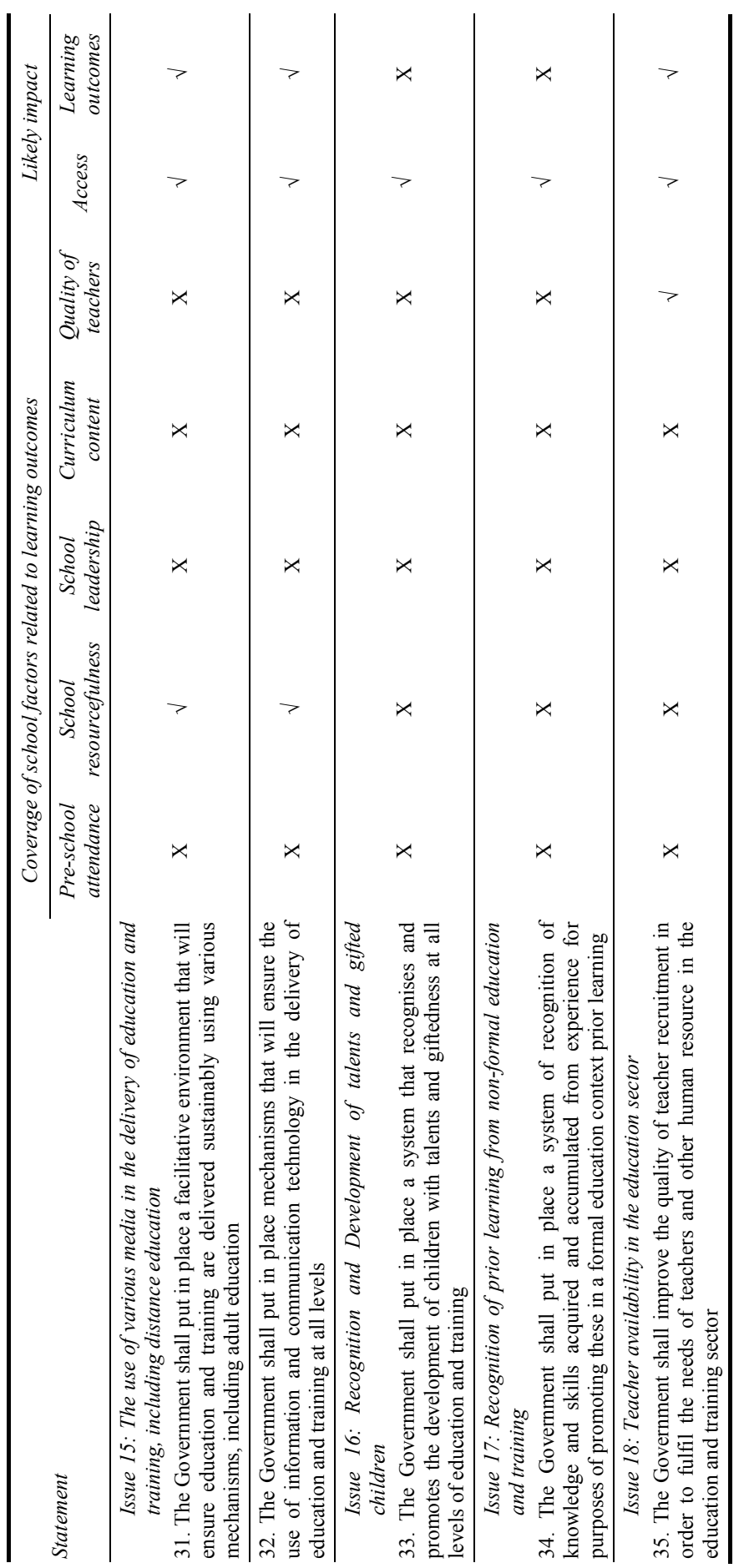


Appendix: Categorisation of policy statements into school factors related to learning outcomes (continued)

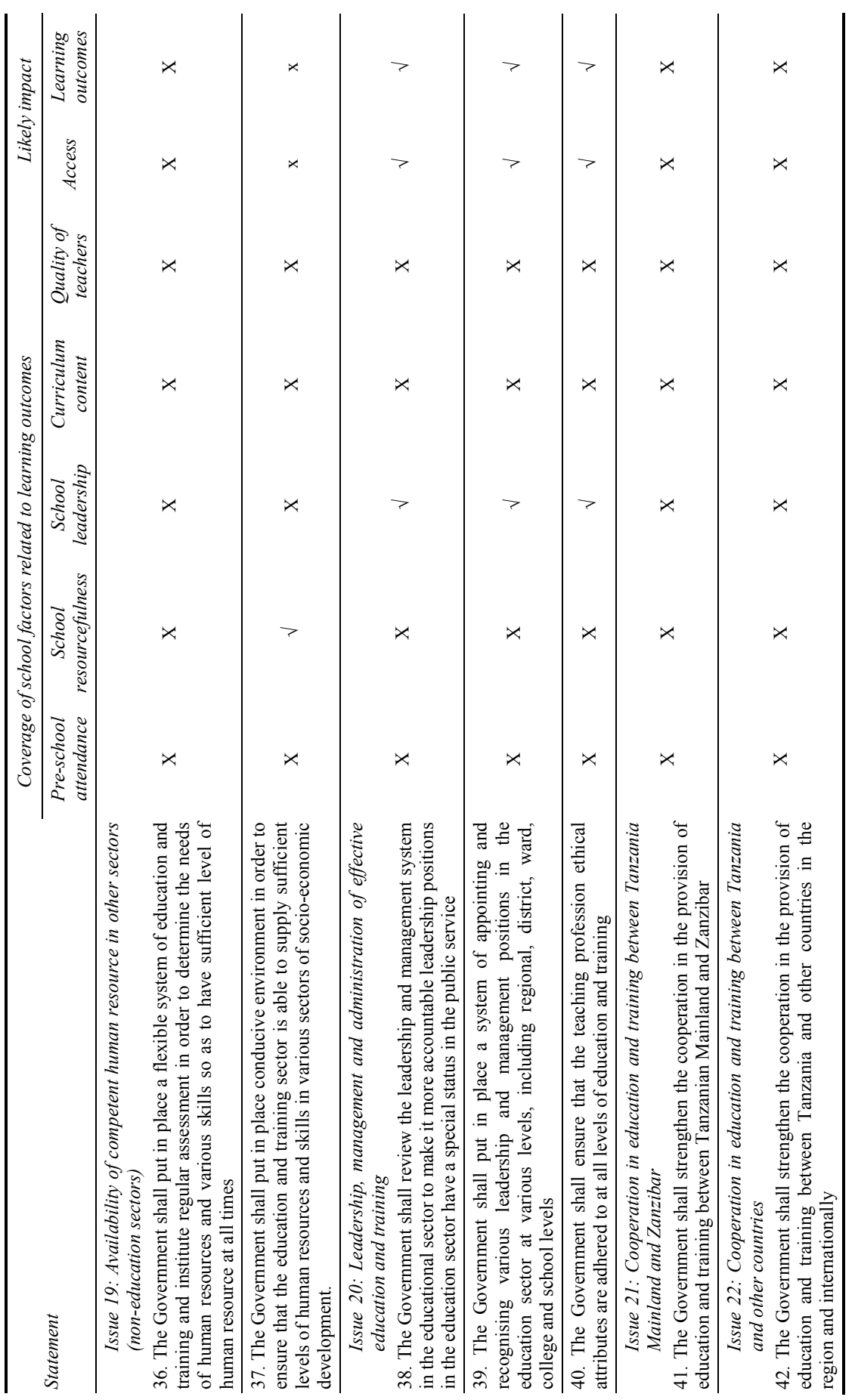


Appendix: Categorisation of policy statements into school factors related to learning outcomes (continued)

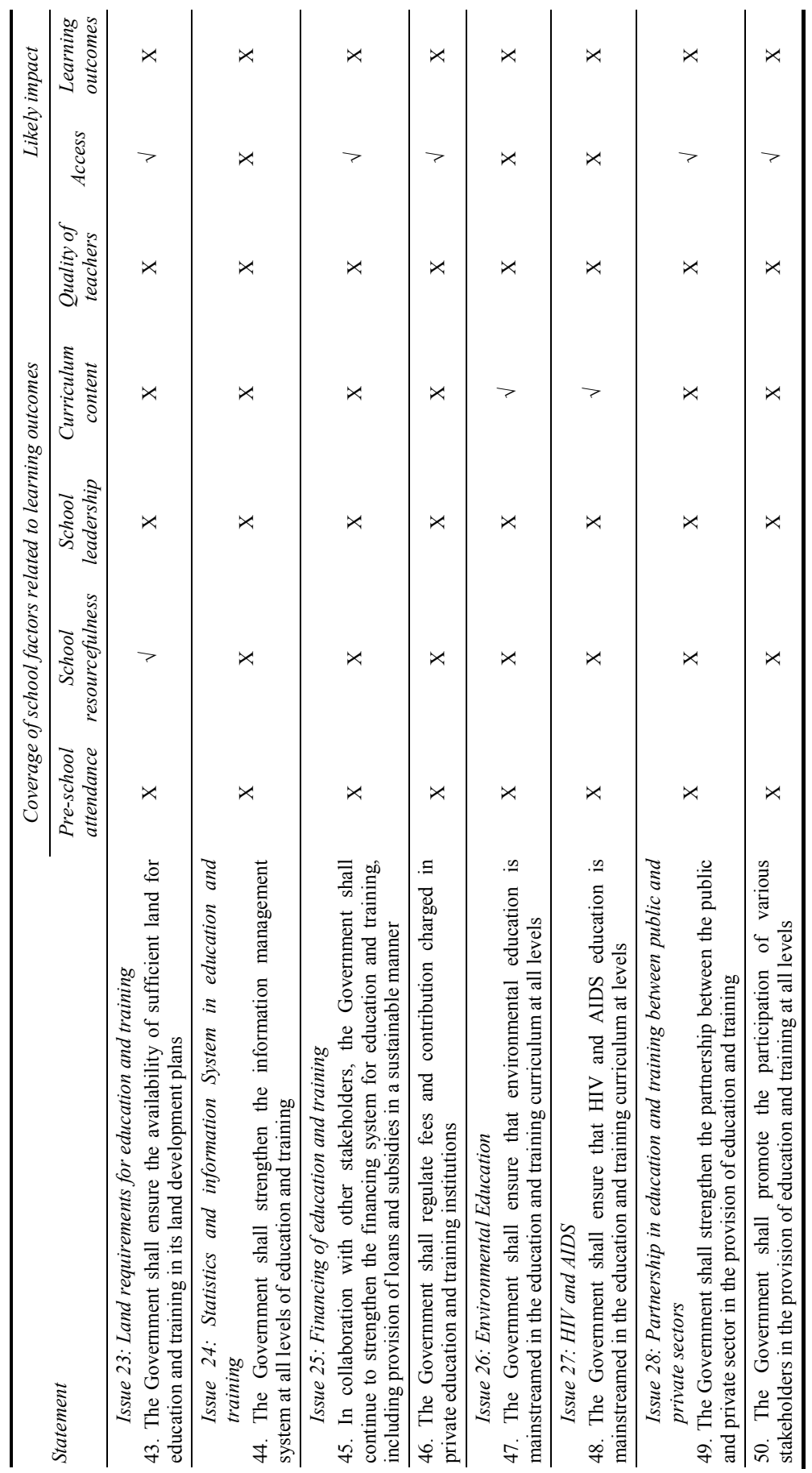

